\title{
Improving situational awareness for floods: Monitoring using satellite data in the boreal region
}

\author{
Juval Cohen ${ }^{1}$, Kirsikka Heinilä² ${ }^{2}$ Mikko Huokuna $^{2}$, Sari Metsämäki² ${ }^{2}$ Jyri Heilimo $^{1}$ and Mikko Sane ${ }^{2}$ \\ ${ }_{1}^{1}$ Finnish Meteorological Institute, P.O. Box 503, Fl-00101 Helsinki, Finland \\ ${ }^{2}$ Finnish Environment Institute, Latokartanonkaari 11, Fl-00790 Helsinki, Finland
}

\begin{abstract}
Space-borne remote sensing techniques enable a near real-time mapping of floods cost-efficiently. Synthetic Aperture Radar (SAR) and optical sensors are the most suitable for flood detection, however, SAR has become more popular, due to the independence of sunlight and weather conditions, and the increasing data availability. Typical spring floods occurred in northern Finland during 2018. Various remote sensing sources were utilized for monitoring and damage estimation of the flooding. Floods were mapped with the SAR based Finnish Flood Centre's Flood Detection Algorithm (FC-FloDA), a standard threshold-based approach applied to Sentinel-1, and a visual interpretation of Sentinel-2 images. In addition, flood maps from the Copernicus Emergency Management Service (EMS) and aerial photographs from the city of Tornio were ordered. The flood products and interpretations were compared, and a deeper accuracy assessment was conducted for the FC-FloDA maps. FC-FloDA was, in general, the most successful in detecting floods within the test areas. The EMS product and the Sentinel-1 interpretation worked well in open areas, but they did not detect floods in forests. The superiority of Flood Centre's product is mainly based on the adaptation of the algorithm to northern boreal environments and the selection of HH-polarized SAR data instead of VV-pol.
\end{abstract}

\section{Introduction}

Floods during the snowmelt season are a well-known natural phenomenon experienced almost every spring in Finland, causing damages to e.g. agriculture, road network and buildings. Changing climate increases floods in major central lakes and their outflow rivers due to increased precipitation (Veijalainen, et al., 2010). The flood damages are likely to multiply if flood risk management measures are not continued and implemented as planned (Parjanne, et al., 2018). The floods are typically caused by overflowing rivers, due to the combination of melting snow, low water infiltration in partly frozen soil and packed ice along the rivers blocking the water flow (Krasovskaia \& Gottschalk, 2002; Flerchinger, et al., 2005; Beltaos, et al., 2012; Lindenschmidt, et al., 2018). Space-borne remote sensing techniques enable a near realtime mapping of flooded areas cost efficiently. These flood maps can be beneficial to emergency personnel operating during a flood event, as well as to landowners and farmers when planning preventative and recovery actions. Flood maps can also be used by insurance companies when handling flood related claims, and by other private or public sectors for community, agriculture, land use, communication and forestry planning. Flood maps also enable calibration and validation of hydraulic model-based

\footnotetext{
${ }^{a}$ Corresponding author: Juval.Cohen@fmi.fi

DOI 10.3311/FLOODRisk2020.7.4
}

(static) flood hazard maps, and flood maps of previous years yield more accurate prediction of flood progress.

The Flood Centre, jointly run by the Finnish Environment Institute (SYKE) and the Finnish Meteorological Institute (FMI) supports the flood situation awareness nationally. It provides many services and products, e.g. forecasts, warnings and flood maps, to the local authorities, such as the Regional Centres for Economic Development, Transport and Environment (ELY) Centres, municipalities, rescue services and others. The past flood events in Finland have shown that a successful flood risk management relies on effective information systems, and up-to-date information is essential for emergency services. Therefore, in addition to the water system forecasts, flood warnings and static (modelled) flood maps, near-real time information about inundated areas and ice situation have significant role in maintaining an overview of the flood situation. Especially river ice jams can induce flooding in the boreal region. In addition to flood detection, SAR imagery can be used to define the locations of ice jams and to detect different types of river ice covers (Unterschultz, et al., 2009; Lindenschmidt \& Li, 2019). The knowledge of flood situation as well as river ice cover will assist the authorities to make correct and well-timed decisions.

Synthetic Aperture Radar (SAR) and optical sensors are the most suitable for flood detection. Recently 
however, the use of SAR has gained popularity over the optical sensors, mainly due to the independence of sunlight and weather conditions, as well as due to the rapid increase in the availability of SAR data. Moreover, SAR sensor enables better detection accuracy in forests compared to the optical, because the microwave signal has a better penetration capability through the forest canopy. Existing methods and approaches for space-borne flood detection in general, and SAR-based flood mapping in particular, have been recently reviewed by Refice et al. (2018), Tsyganskaya et al. (2018) and Shen et al. (2019), and earlier by Huang et al. (2018), Klemas (2015) and Martinis et al. (2015). Recent advancements related to satellitebased flood mapping and monitoring have also been presented in a Special Issue by Domeneghetti et al. (2019).

The most popular methods used in SAR flood mapping are based on applying appropriate threshold values on the backscatter observations, classifying the pixels to flooded or non-flooded terrain. Floods in open treeless areas can be separated from non-flooded areas due to very low backscatter caused by specular reflection of the SAR radiation over the water surface. In contrary, floods in forests can be separated from non-flooded areas due to relatively high backscatter caused by corner reflection of the radar signal between the water surface and the tree trunks (Richards, et al., 1987; Voormansik, et al., 2014; Martinis \& Rieke, 2015; Hess, et al., 1990; Townsend, 2001; Engheta \& Elachi, 1982). HH- and VV-polarizations are generally preferable in flood mapping compared to $\mathrm{HV}$ and VH cross polarizations (Evans, et al., 1986; Wu \& Sader, 1987; Kuga, et al., 1990; Henry, et al., 2006). Yet, $\mathrm{HH}$ is the optimal polarization for detecting floods in forests, due to better penetration of the forest canopy compared to VV-pol and cross-polarizations (Wang, et al.,
1995; Bourgeau-Chavez, et al., 2001; Townsend, 2002; Lang \& Kasischke, 2008; Pierdicca, et al., 2013). Other factors, such as the signal frequency (Wang, et al., 1995; Voormansik, et al., 2014), incidence angle (Lang, et al., 2008), forest density and tree height (Cohen, et al., 2016; Pulliainen, et al., 1999), season (leaf-on, leaf-off) as well as soil moisture and surface roughness (Ulaby, et al., 1981; Ulaby, et al., 1982; French, et al., 1996) affect the ability of the SAR to detect floods (Henderson \& Lewis, 2008), and therefore they need to be considered in a proper flood detection algorithm.

Several flood events occurred in northern Finland during spring 2018. In this study we have examined and compared flood maps from different remote sensing sources and performed a deeper assessment of the flood maps generated by the Finnish Flood Centre. Flood maps were ordered from the Finnish Flood Centre and from the Copernicus Emergency Management Service (EMS) (EMS, 2020). In addition, flood maps were derived from Sentinel-1 data using a standard threshold-based approach. Due to favourable cloud conditions during the flood events, flooded areas were also visible in optical highresolution Sentinel-2 data. Aerial photographs collected by the city of Tornio were used for validation in specific locations. In this paper, chapter 2 introduces the test areas and the datasets used. Chapter 3 explains the SAR Flood Detection Algorithm developed by the Finnish Flood Centre (FC-FloDA), the methods used for extracting flooded areas from Sentinel-1 images, and the methods used for assessing the flood detection accuracies. Chapter 4 presents the flood detection assessment results for the different products and sensors, and chapter 5 concludes the study and the results.

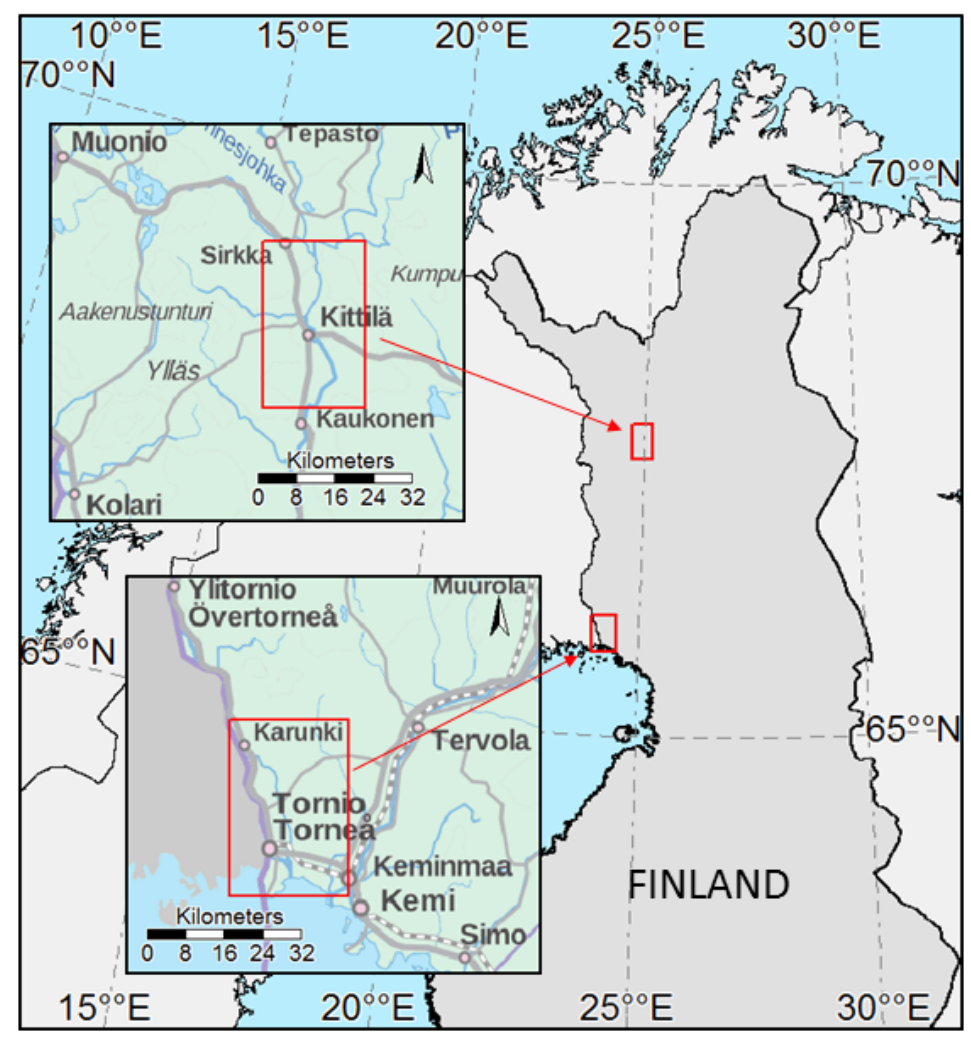

Figure 1: The Kittilä and Tornio test areas. 


\section{Test areas and data}

Flood mapping was performed in two test areas located in northern Finland; Tornio and Kittilä (Figure 1). The size of the test areas was approximately $20 \times 30 \mathrm{~km}$. In both test areas, flooding occurred mainly alongside the major rivers; Tornionjoki in Tornio and Ounasjoki in Kittilä. Tornionjoki river is the national border between Finland and Sweden, and it flows southwards between the cities Tornio on the Finnish side and Haparanda on the Swedish side, before discharging into the Gulf of Bothnia. Ounasjoki flows through the town of Kittilä and continues southwards until it merges with Kemijoki and finally reaches the Gulf of Bothnia near the town of Kemi. Both test areas represent typical boreal environments, including mainly forests, open bogs and agricultural fields, as well as some populated areas.

Two Cosmo-Sky-Med Stripmap HH-polarisation SAR images acquired on the $17^{\text {th }}$ of May, one from Tornio and one from Kittilä, were used in FC-FloDA. As ancillary information, FC-FloDA uses forest canopy cover and tree height maps generated from LiDAR data collected by the National Land Survey (NLS) of Finland, a Digital Elevation Model (DEM) with a spatial resolution of $2 \mathrm{~m}$ (KM2) from NLS, and the Finnish Corine Land Cover (CLC) product. Flood maps for the Tornio test area were ordered from Copernicus EMS. The EMS flood maps have been derived from one Sentinel-1 image acquired on the $17^{\text {th }}$, and two Radarsat- 2 images acquired on the $17^{\text {th }}$ and the $18^{\text {th }}$ of May. In addition, flood mapping was performed with Sentinel-1 GRD IW VV-polarization SAR data and Sentinel-2 optical images. The Sentinel-1 and -2 images from Tornio were acquired on the $17^{\text {th }}$ and $16^{\text {th }}$ of May, and from Kittilä on the $18^{\text {th }}$ and $16^{\text {th }}$ of May, respectively. Drone aerial photographs collected by the city of Tornio on the $15^{\text {th }}$ of May were used for visual validation of the flood maps in Tornio.

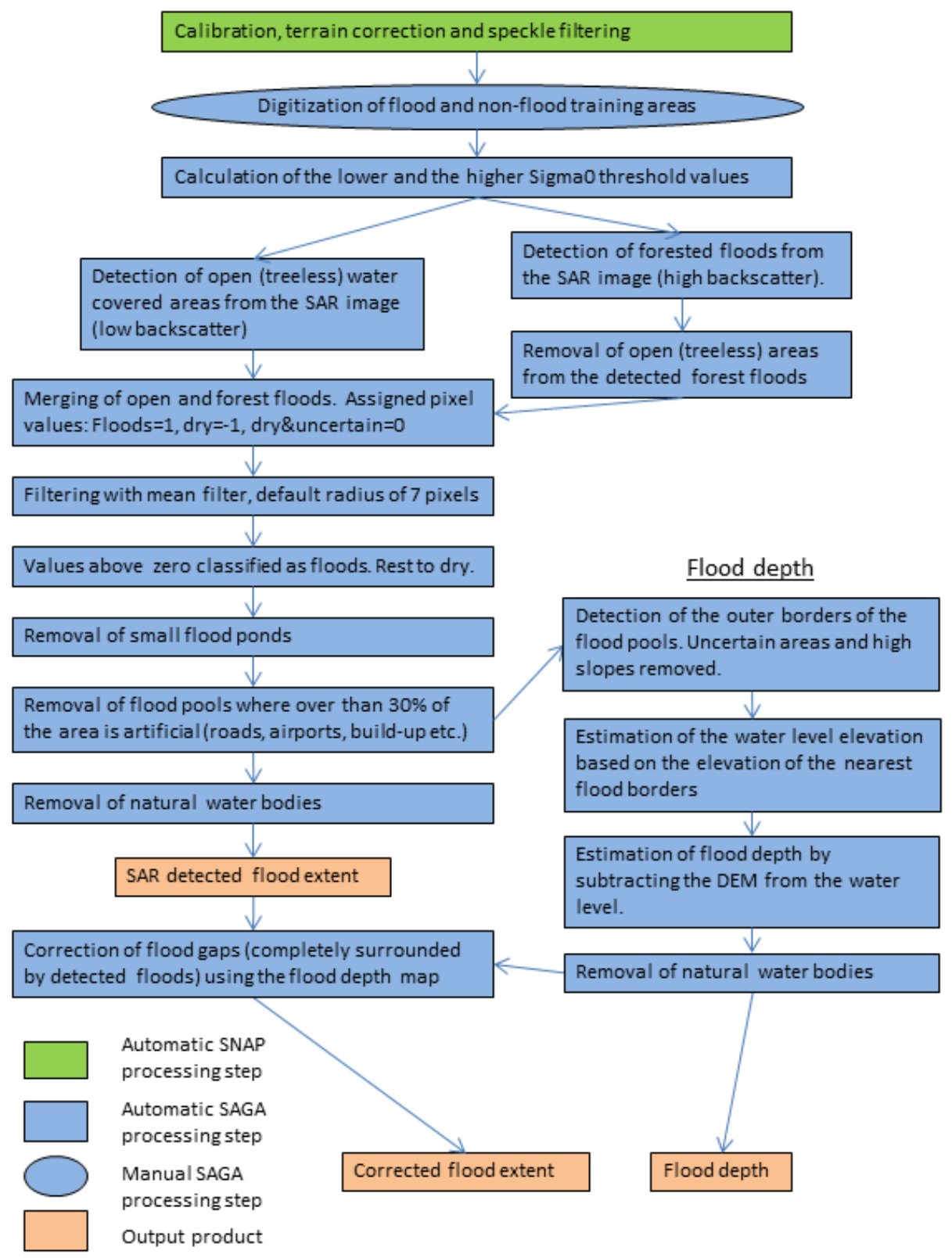

Figure 2: A diagram showing the structure and the output products of FC-FloDA. Uncertain area refers to sparse or low-tree semiforested areas where SAR flood detection is problematic (Cohen et al., 2016)

\footnotetext{
${ }^{a}$ Corresponding author: Juval.Cohen@,fmi.fi

DOI 10.3311/FLOODRisk2020.7.4
} 


\section{Methods}

In this chapter, FC-FloDA, the flood detection algorithm developed by the Finnish Flood Centre for mapping floods in open and forested boreal environments, is first introduced. A diagram showing the structure of FCFloDA is presented in Figure 2. Pre-processing of the SAR data, including calibration, terrain correction and speckle filtering, is done with the SNAP (Sentinel Application Platform) software. The actual satellite data processing is done in FMI National Snow Data Centre (NSDC), Tähtelä, Sodankylä. The algorithm can be roughly divided into three parts: 1) Detection of flood extent by analysing the SAR backscatter $\left(\sigma^{0}\right)$ image (see section 3.1), 2) estimation of flood depth by assimilating a high-resolution DEM with the SAR detected flood areas (see section 3.2), and 3) correction of the flood extent by using the retrieved flood depth (see section 3.3). After processing, the flood maps are disseminated through Flood Centre's user interface, as described in section 3.4. Section 3.5 explains the methods used for extracting flood maps from Sentinel-1 images, and finally, section 3.6 describes how the accuracy of the flood maps was assessed.

\subsection{Flood Extent}

Flooded areas are separated from dry land by applying two threshold values on the sigma naught backscatter $\left(\sigma^{0}\right)$ image: A lower threshold value (thr1) and a higher threshold value (thr 2 ) are used to separate forest floods and open floods from non-flooded areas, respectively. In order to define the optimal threshold values, training areas representing floods in open areas, forest floods and nonflooded areas are first digitized over the SAR backscatter images. The selection of these training areas is the only manual step in the FC-FloDA process. The optimal lower threshold value (thr 1 ) is calculated by the algorithm based on the observations of the open flood $(O F)$ training area and the non-flooded $(N F)$ training area, by finding the minimum of the error function:

$$
\min \left[W O F_{\sigma^{0}>t h r 1} /_{O F_{a l l}}+N F_{\sigma^{0}<t h r 1} / N F_{a l l}\right],
$$

where $W$ is a weight factor controlling the relation between omission (floods not detected) and commission (falsely detected floods) errors. $O F_{\sigma^{0}>t h r 1}$ is the number of open flood observations where $\sigma^{0}$ is higher than thr 1 , $O F_{\text {all }}$ is the total number of open flood observations, $N F_{\sigma^{0}<t h r 1}$ is the number of non-flooded observations where $\sigma^{0}$ is lower than $t h r 1$ and $N F_{\text {all }}$ is the total number of non-flooded observations. The optimal higher threshold value (thr 2 ) is calculated as in eq. 1, but based on the observations of the forest flood $(F F)$ training area and the non-flooded $(N F)$ training area:

$$
\min \left[W F F_{\sigma^{0}<t h r 2} / F F_{\text {all }}+N F_{\sigma^{0}>t h r 2} / N F_{a l l}\right]
$$

where $F F_{\sigma^{0}<t h r 2}$ is the number of forest flood observations where $\sigma^{0}$ is lower than $t h r 2, F F_{\text {all }}$ is the total number of forest flood observations and $N F_{\sigma^{0}>t h r 2}$ is the number of non-flooded observations where $\sigma^{0}$ is higher than $t h r 2$. The weight factor $(W)$ was set to 2 , in order to detect more flooded areas at the expense of higher false commission error rate. This was preferred, because in the following steps of FC-FloDA, small flood polygons are removed, and therefore the commissions errors are more likely to be corrected than omission errors.

Based on LiDAR based forest maps, the area is classified into three forest classes; 1) open treeless areas, 2) sparse or low tree forests and 3) dense forests. After defining the $\sigma^{0}$ threshold values and the forest classes, all pixels with values below $t h r 1$ or above $t h r 2$ are classified as water/flood, and the rest as non-flooded areas. Areas identified as non-flooded in sparse or low tree forests are classified as uncertain, because in those areas SAR flood detection is problematic (Cohen, et al., 2016). Smooth surfaces such as airport runways or roads are often falsely interpreted as water due to specular reflection causing low $\sigma^{0}$, and some built-up areas are often falsely classified as forest floods due to strong corner reflection from buildings. Hence, detected floods over roads, airports or other urban areas were not accepted. Detected forest floods (values above $t h r 2$ ) were accepted only if the area was forested according to the forest data. Also, small ponds (less than 0.5 hectares) were removed. Finally, natural water bodies were masked from the water/flood map using CLC data.

\subsection{Estimation of Flood Depth}

In order to estimate the flood depth, the outer borders of the SAR detected inundated areas (including natural water bodies such as rivers and lakes) were first located. This was done first by filling small gaps inside flooded areas i.e. completely surrounded by floods (hereinafter referred to as flood gaps), and then, applying a Laplace ( $1^{\text {st }}$ derivative) filter. The ground elevation in the outer borders of the flood areas is then extracted from a high-resolution DEM (KM2). The elevation of the flood water level for each flood cell was then estimated by finding the elevation of the nearest flood border, ignoring borders of uncertain flood areas and borders where the ground slope was more than $10 \%$. The flood depth of each pixel is then calculated by subtracting the DEM from the flood water level grid. 


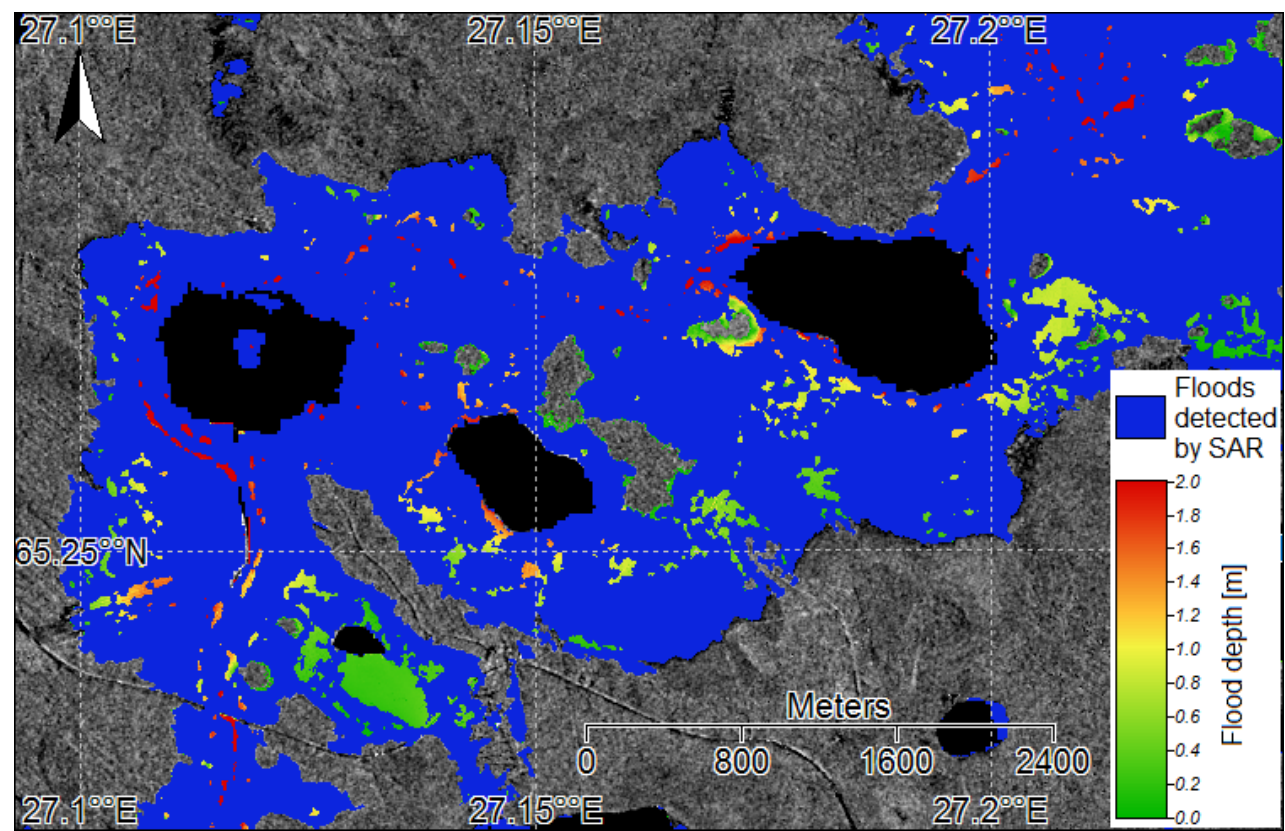

Figure 3: Flood gap correction. Blue areas show forest and open flood areas detected from the SAR image after filtering and removal of natural waterbodies, before the flood gap correction. Green-yellow-red graduated colors show flood gaps not detected by SAR and corrected using the flood depth map. SAR backscatter image is shown on the background, where lakes appear as large black areas.

\subsection{Correction of Flood Gaps}

A flood gap correction was applied on the SAR detected flood extent map by using the derived flood depth. A flood gap in the SAR interpretation (an area detected as non-flooded, but completely surrounded by detected floods) was corrected to flooded, if the derived flood depth was over zero. As seen in Figure 3, there are typically many small flood gaps inside the detected flood areas. Some of these gaps are in fact flooded, but they have not been detected by the SAR due to backscattering similar to dry ground.

\subsection{Dissemination}

After the generation of the flood maps, they are automatically transferred and published in the situation awareness map developed by SYKE. The map brings together the essential information on floods under a single user interface. The application includes an array of floodrelated information that serves the duty officer managing the flood event, such as remote sensing based detection, damage estimations, live cameras, in situ observations and photographs, road traffic incidents caused by the floods and georeferenced social media. In addition, the flood extent is published as a part of national public flood map service (Figure 4) (Sane, et al., 2014).

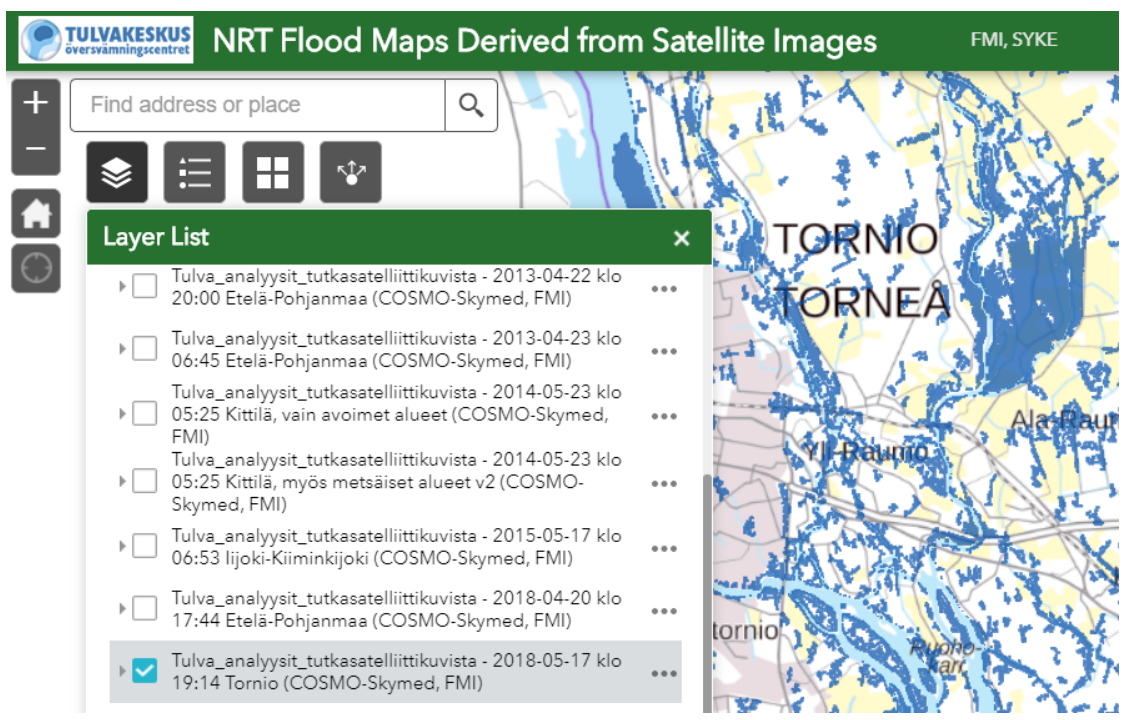

Figure 4: The operative flood map service for presenting the NRT flood maps and the latest analysis from the City of Tornio in the 


\subsection{Sentinel-1 SAR -based flood detection}

The usability of flood interpretation based on Sentinel1 SAR images was investigated in the same areas; Tornio and Kittilä, where FC-FloDA and EMS flood maps were available. Sentinel-1 provides SAR data free-of-charge with regular operational availability, but only using VV and $\mathrm{VH}$ (vertical-horizontal) polarizations in its Interferometric Wide Swath (IW) acquisition mode over land areas. The flood mapping procedure followed ESA guidelines. First, the backscatter coefficient values of Level-1 Ground Range Detected (GRD) IW images were calibrated. The images were filtered using Lee filter with window size of $7 \times 7$ and georectified using KM10 digital elevation model of NLS. In both study areas; Kittilä and Tornio, the $\sigma^{0}$ threshold was set to $4 \mathrm{E}-2$ to extract pixels covered by water. Natural waterbodies were then removed using CLC 2018 data, leaving only flooded areas.

\subsection{Flood map accuracy assessment}

A rough assessment was first made for the different flood products and derived flood maps by a visual comparison between FC-FloDA, EMS and Sentinel-1 based flood maps, as well as HH-polarisation Cosmo SkyMed SAR backscatter images, Sentinel-2 optical false color images, drone photographs and forest density maps. After a rough accuracy estimation, the FC-FloDA flood maps were further assessed for the Kittilä test area using a quantitative analysis against flood reference areas representing the true flood conditions, forest maps and land cover classification data.

The flood reference areas were manually digitized over a Sentinel-2 false color RGB image with a combination of $\mathrm{R}=\mathrm{NIR}, \mathrm{G}=\mathrm{Green}$ and the $\mathrm{B}=\mathrm{Red}$ channels. The reference areas were then further inspected, and if needed, corrected using a high-resolution DEM. The total size of the reference flood areas was $16.4 \mathrm{~km}^{2}$, including land cover classes and forests typical for the test region.

\section{Results}

Figure 5 and Figure 6 show two examples of flooded sites in Tornio region. Floods detected by FC-FloDA, EMS and Sentinel-1 are marked with green, yellow and magenta orthogonal lines, respectively, over a Cosmo SkyMed HH-polarization backscatter image. Optical false color Sentinel-2 images are also shown for the same sites. The site in Figure 5 is from a river confluence where the Keskijoki and Järvijoki rivers merge with Liakanjoki river.

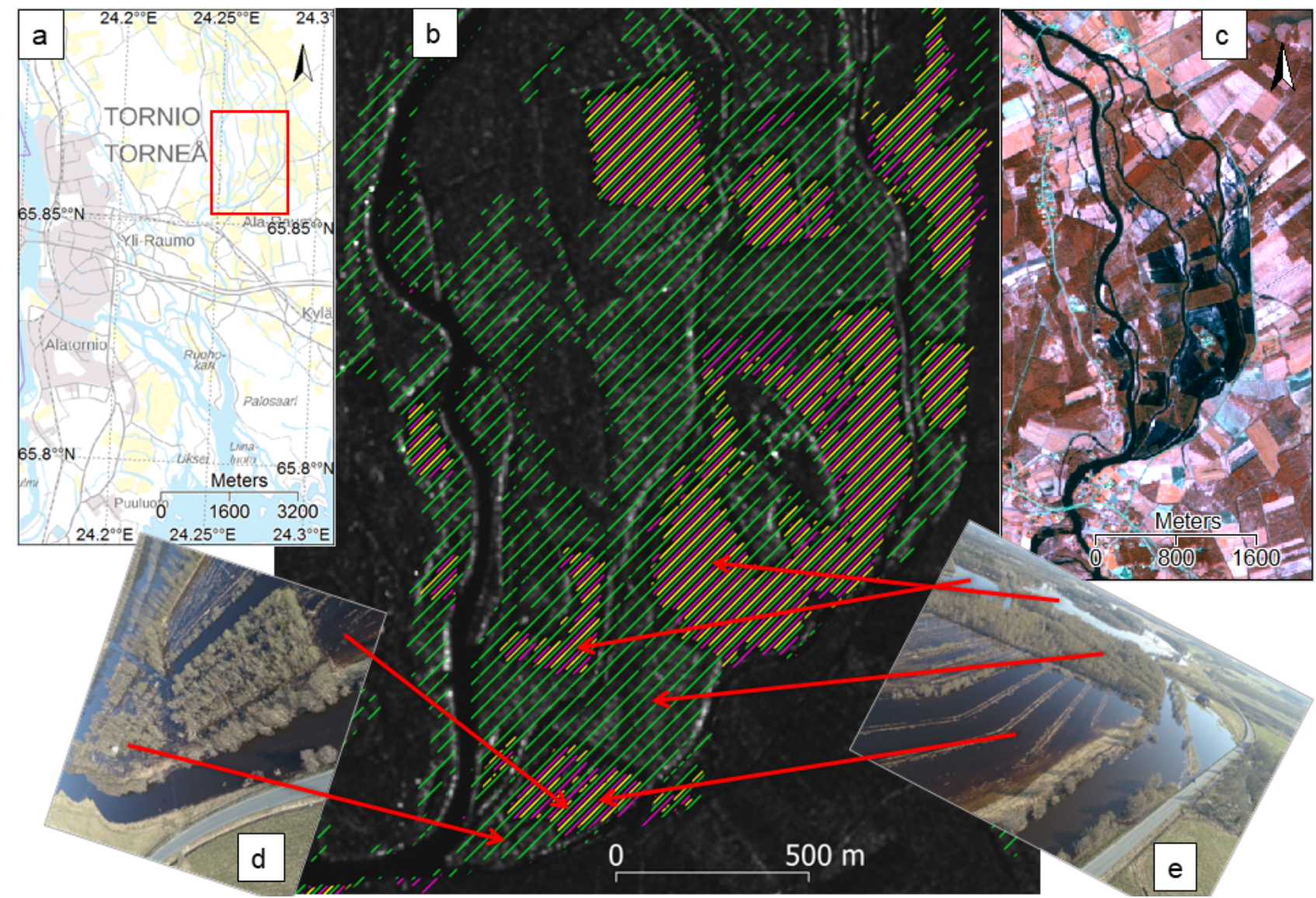

Figure 5: Flood mapping in Heinijankantie, Tornio, during 15-18.5.2018. a) The location of the floods observed in images b-e. b) Image shows floods detected by FC-FloDA on the $17^{\text {th }}$ of May with green, floods detected by EMS on the $17^{\text {th }}$ (Sentinel-1) and $18^{\text {th }}$ (Radarsat-2) of May with yellow, and floods extracted from Sentinel-1 on the $17^{\text {th }}$ of May with magenta orthogonal lines, over a Cosmo Sky-Med backscatter image. c) RGB false color image of Sentinel-2 from the $16^{\text {th }}$ of May, with the combination of R=NIR, $\mathrm{G}=$ green and $\mathrm{B}=$ red channels. $\mathrm{d}$ )-e) True color drone images collected by the city of Tornio on the $15^{\text {th }}$ of May.

\footnotetext{
${ }^{a}$ Corresponding author: Juval.Cohen@fmi.fi

DOI 10.3311/FLOODRisk2020.7.4
} 
The site in Figure 6 is from Napinpää, located on the Finnish side of on the Tornionjoki river. Figure 7 shows the results from the Kittilä test area. Floods detected by FC-FloDA and Sentinel-1 are marked with green and magenta orthogonal lines, respectively, over a Cosmo SkyMed HH-polarization backscatter image. A partly clouded optical false color Sentinel-2 image is also shown. The town of Kittilä is located in the riverbanks of the Ounasjoki river, which is often flooded during the spring.

All sites contain open and forested terrain, as seen in the aerial photographs (Figure $5 \mathrm{~d}$ and e), and in the canopy cover maps (Figure $6 \mathrm{c}$ and Figure $7 \mathrm{c}$ ). As seen in Figure 5 b, Figure 6 b and Figure 7 b, the FC-FloDA detects both open and forested floods, but EMS and Sentinel-1 detect floods only in open (non-forested) areas. The EMS product was not ordered for Kittilä, however, based on the similarity of the EMS and the Sentinel-1 interpretations observed in Tornio, we can assume that EMS flood detection in Kittilä would have been very similar to the interpretation of Sentinel-1. By a visual inspection of the optical images (Figure 5 c, Figure $6 \mathrm{~d}$ and Figure $7 \mathrm{~d}$ ), floods in open areas can easily be distinguished because they appear darker than the surrounding non-flooded areas. Floods under tree canopy are also somewhat darker compared to non-flooded forests, but the differences between flooded and nonflooded forests are less distinct compared to open areas.

According to an analysis of FC-FloDA results against the flood reference areas in Kittilä, $90 \%$ of the flooded areas were detected. As seen in Figure 8, most of the undetected floods were in semi forested areas (sparse canopy) and in wetlands (marshes and open peatbogs). This supports the results obtained by Cohen et al., 2016, who found that flood detection with X-band $\mathrm{HH}-$ polarization SAR is problematic in semi-forested sparse or low-tree forests.

Figure 9a shows all the chosen flood reference areas over an optical false color image, and images b-e compare the reference areas with detected floods, with a highresolution DEM in the background. As seen in Figure 9b, the vast majority of the floods were detected by FCFloDA. The undetected flood areas, as seen in images c-e of Figure 9, were mostly located in the edges of the flooded areas, where the terrain is most likely partly covered by shallow flood pools and partly by exposed ground. The exposed patches, seen as bright lines in images c-e (Figure 9), cause an increase of the total backscatter, thus disrupting the SAR flood detection. Apart from these shallow floods with partially exposed ground, the flood detection accuracy is expected to increase close to $100 \%$.

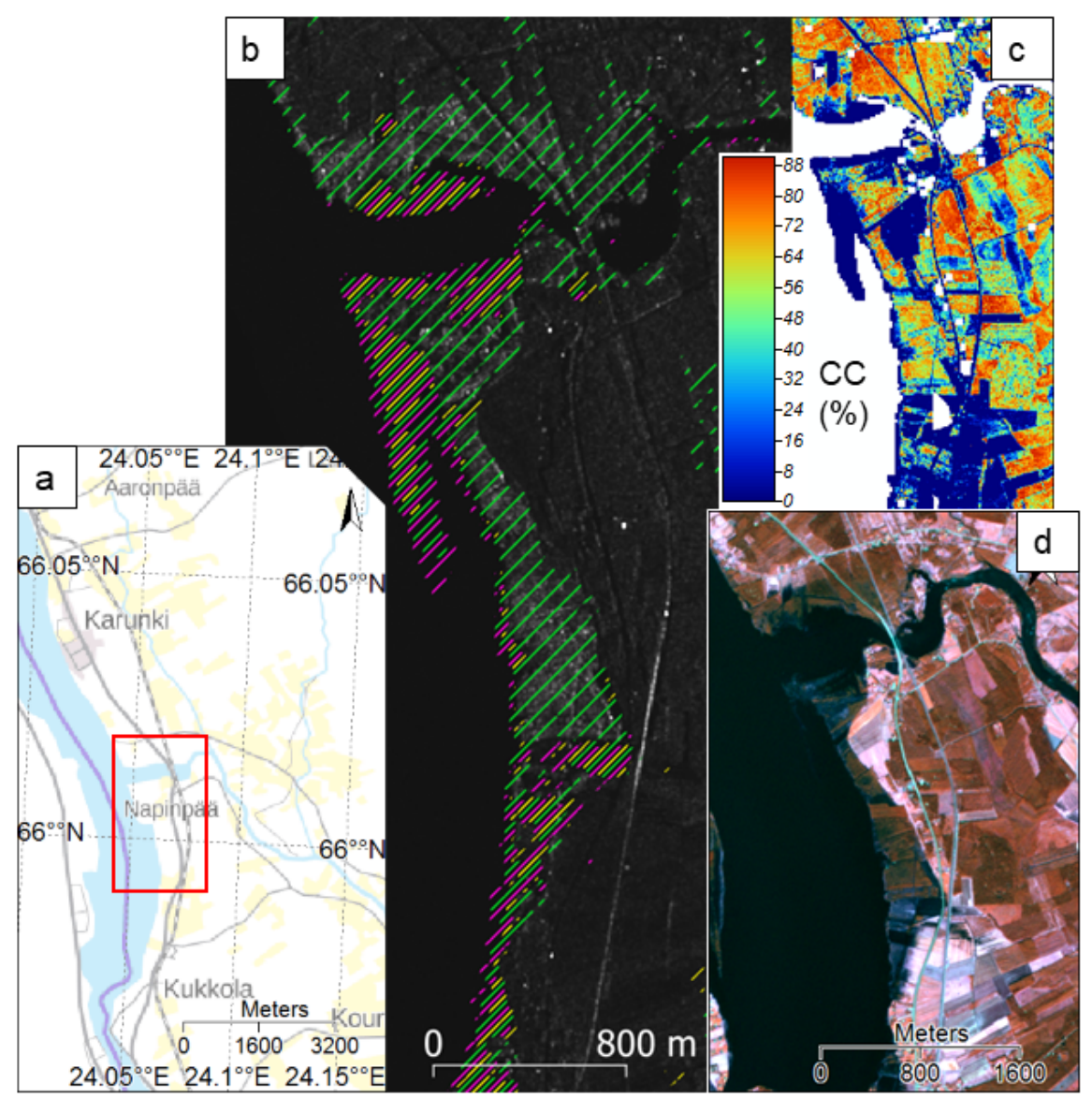

Figure 6: Flood mapping in Napinpää, Tornio, during 17-18.5.2018. a) The location of the floods observed in images b-d. b) Image shows floods detected by FC-FloDA on the $17^{\text {th }}$ of May with green, floods detected by EMS on the $17^{\text {th }}$ (Sentinel-1 and Radarsat-2) and $18^{\text {th }}$ (Radarsat-2) of May with yellow, and floods extracted from Sentinel-1 on the $17^{\text {th }}$ of May with magenta orthogonal lines, over a Cosmo Sky-Med backscatter image. c) Canopy cover map of the area. d) RGB false color image of Sentinel-2 from the $16^{\text {th }}$ of May, with the combination of $R=N I R, G=$ green and $B=$ red channels.

\footnotetext{
${ }^{a}$ Corresponding author: Juval.Cohen@fmi.fi

DOI 10.3311/FLOODRisk2020.7.4
} 


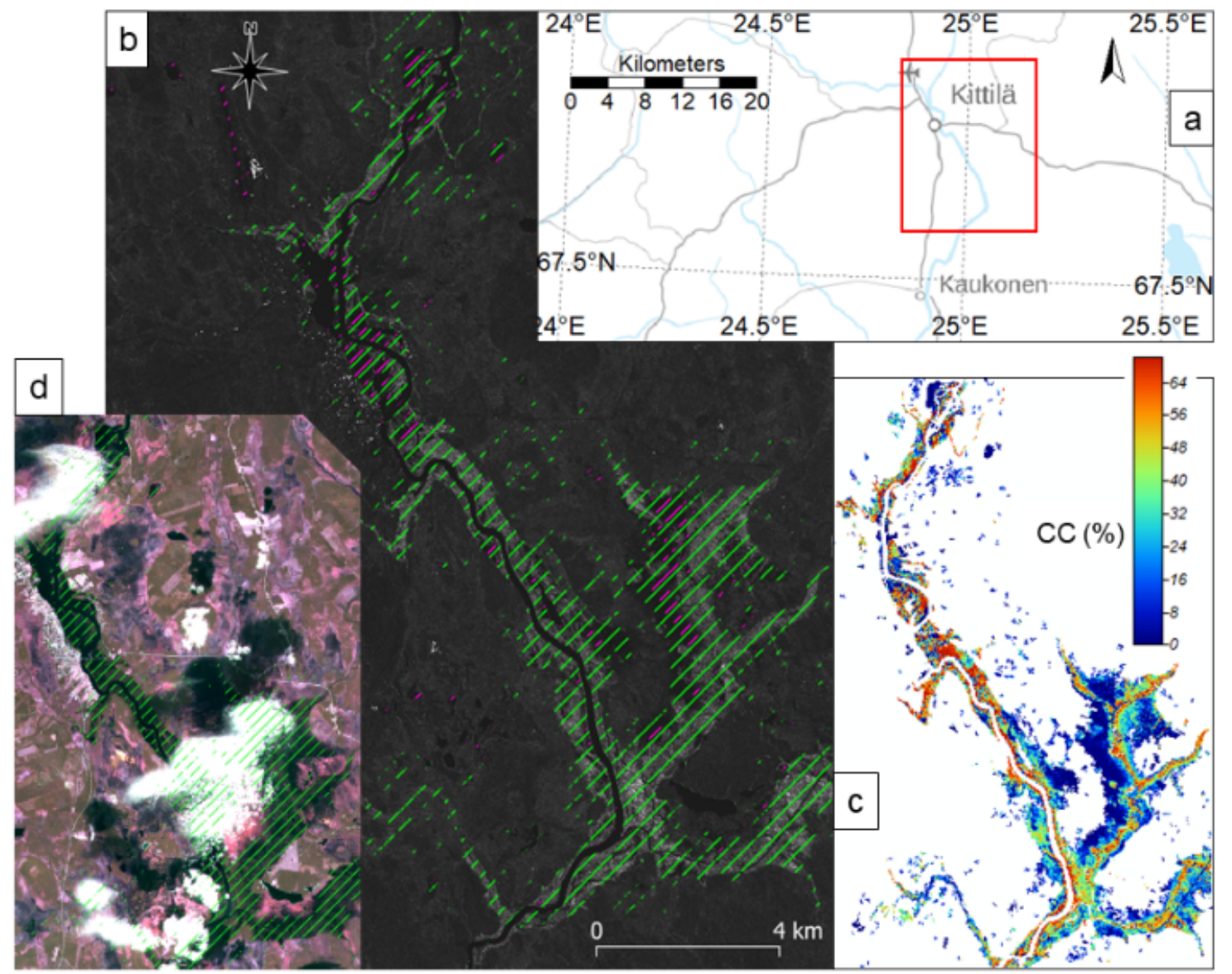

Figure 7: Flood mapping in Kittilä during 16-17.5.2018. a) The location of the floods observed in images b-d. b) Image shows floods detected by FC-FloDA on the $17^{\text {th }}$ of May with green, and floods detected with Sentinel-1 on the $18^{\text {th }}$ of May with magenta orthogonal lines, over a Cosmo Sky-Med backscatter image. c) Canopy cover map of the test area (only areas detected by FC-FloDA).

d) RGB false color image of Sentinel- 2 from the $18^{\text {th }}$ of May, with the combination of $\mathrm{R}=\mathrm{NIR}, \mathrm{G}=$ green and $\mathrm{B}=$ red channels.

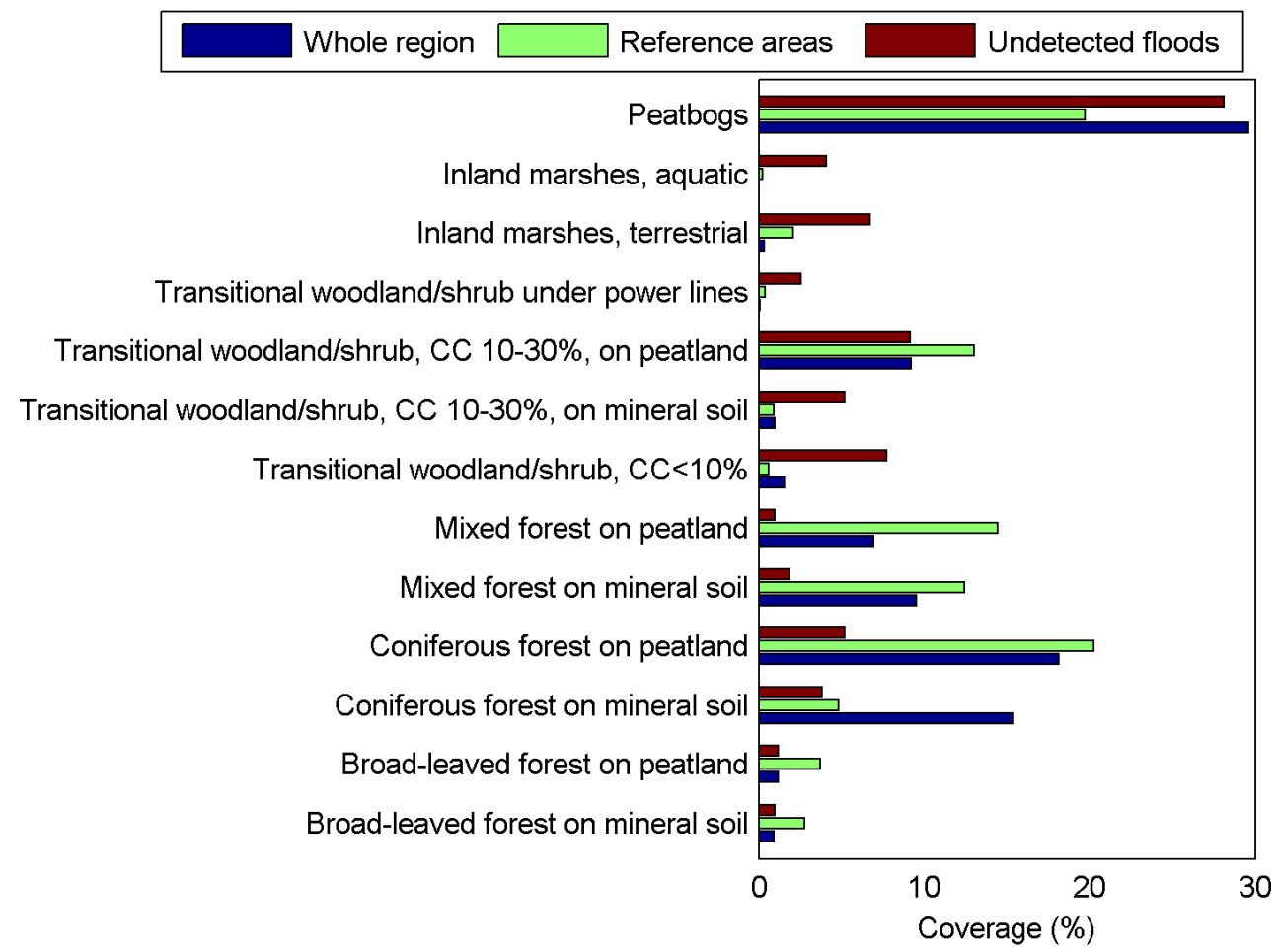

Figure 8: The coverage percentage of the main land cover classes in the whole test region of Kittilä, in the chosen reference flooded areas, and in the undetected floods inside the reference areas. Land cover classes are derived from CLC 2018 data. 

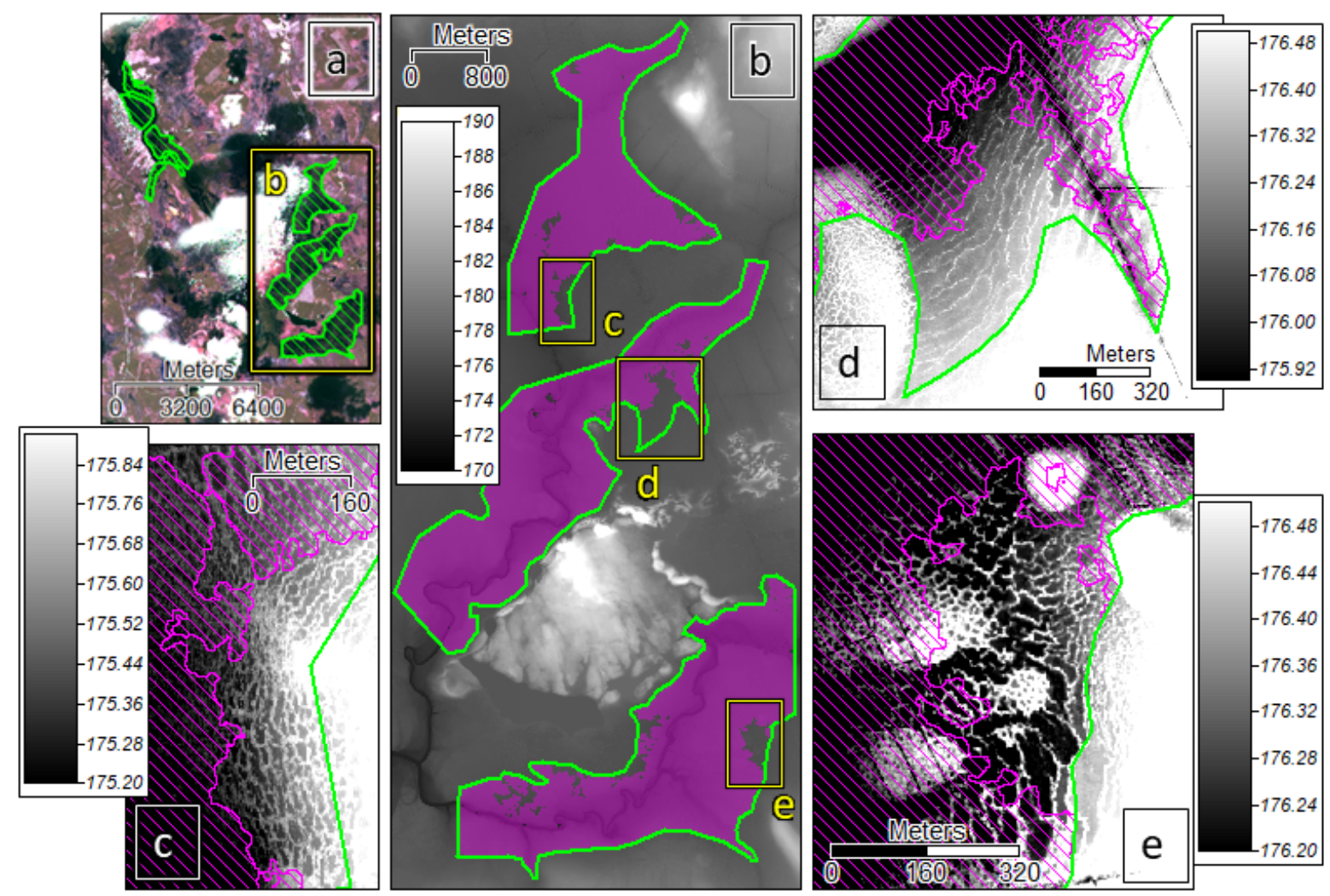

Figure 9: All chosen reference areas over an optical false color image from Kittilä test area (a) and a comparison between reference areas and detected floods over a high-resolution DEM (b-e). The edges of the reference areas are marked with green and the detected floods by FC-FloDA are marked with magenta partly transparent (image b) or diagonal lines (images $c$, d and e). As seen in image $b$, most of the floods were detected by FC-FloDA. Image b shows the location of the three sub-areas c-e, where the detection was relatively poor. The height in m.a.s.l. according to the NLS DEM with $2 \mathrm{~m}$ spatial resolution is shown next to each sub-image.

\section{Conclusions}

Flood maps generated by the Flood Centre were, in general, the most successful in detecting floods within the Tornio and Kittilä test areas. $90 \%$ of the flooded areas, including forest floods, were detected by FC-FloDA. Most of the undetected floods were in the edges of the flooded areas, i.e. in shallow floods, where the ground was most likely partially exposed. EMS flood product worked well in open, non-forested terrain, but did not indicate floods under tree canopy. Flooded areas were visually apparent in the optical Sentinel-2 images. However, in some forested areas, the distinction of floods was less clear. Analysis of the Sentinel-1 VV-polarization data showed that floods in open areas can be detected, but similarly to the EMS product, floods in forests were less visible.

The superiority of the Flood Centre product over the others in boreal environments is mainly based on the adaptation of the algorithm to the boreal forest region, by adding a separate mechanism targeting forest flood detection, in addition to the more general case of floods in open areas. SAR sensor is preferable over optical, due to frequent cloud cover in the region. The use of $\mathrm{HH}-$ polarization instead of $\mathrm{VV}$-pol lead to better detection in forests, due to better penetration of $\mathrm{HH}$-pol signal through the forest canopy (Wang, et al., 1995; Bourgeau-Chavez, et al., 2001; Townsend, 2002; Henry, et al., 2006; Pierdicca, et al., 2013). For example, the VV-polarized Sentinel-1 data is less applicable for the detection of floods in forests. Nevertheless, we found that when combined with VH-pol, it is possible to detect some of the forest floods also with VV-pol. This approach can therefore be used to support the flood monitoring in the possible absence of HH-pol. As these are only preliminary results, the investigation continues and will be reported further on.

The increasing amount of satellite sensors providing freely available and continuous observations have encouraged investigations assessing their suitability for flood monitoring (Notti, et al., 2018; DeVries, et al., 2017; Twele, et al., 2016; Tsyganskaya, et al., 2019; Ruzza, et al., 2019; Reksten, et al., 2019; Kordelas, et al., 2018; Clement, et al., 2018; Uddin, et al., 2019; Du, et al., 2016). Considering spatial and temporal resolution, Sentinel-1 and Sentinel-2 have the potential to significantly improve flood monitoring capabilities. In particular, the suitability of these data for detecting forest floods in the boreal region should be further studied. In order to improve flood risk management in the boreal region, the usability of Sentinel1 for detecting existing ice jams, and Sentinel-2 for assessing the risk of ice jam formation along the river, should also be investigated. This information, in addition to flood maps, may be essential when measures to prevent flood damages during river ice break-up are planned.

\section{References}

Beltaos, S., Tang, P. \& Rowsell, R., 2012. Ice jam modelling and field data collection for flood forecasting in the Saint John River, Canada. Hydrol. Process., Volume 26, pp. 2535-2545. 
Bourgeau-Chavez, L. L. et al., 2001. Analysis of spaceborne SAR data for wetland mapping in Virginia riparian ecosystems. International Journal of Remote Sensing, 22(18), pp. 3665-3687.

Clement, M., Kilsby, C. \& Moore, P., 2018. Multitemporal synthetic aperture radar flood mapping using change detection. Journal of Flood Risk Management, 11(2), pp. 152-168.

Cohen, J. et al., 2016. Implications of boreal forest stand characteristics for X-band SAR flood mapping accuracy. Remote Sensing of Environment, Volume 186, pp. 47-63.

DeVries, B. et al., 2017. Automated Quantification of Surface Water Inundation in Wetlands Using Optical Satellite Imagery. Remote Sensing, 9(8).

Domeneghetti, A., Schumann, G. J. -P. \& Tarpanelli, A., 2019. Preface: Remote Sensing for Flood Mapping and Monitoring of Flood Dynamics. Remote Sensing, 11(8).

$\mathrm{Du}, \mathrm{Y}$. et al., 2016. Water Bodies' Mapping from Sentinel-2 Imagery with Modified Normalized Difference Water Index at 10-m Spatial Resolution Produced by Sharpening the SWIR Band. Remote Sensing, 8(4).

EMS, 2020. Copernicus Emergency Management Service.

Available at: https://emergency.copernicus.eu/

[Online]

Engheta, N. \& Elachi, C., 1982. Radar Scattering from a Diffuse Vegetation Layer over a Smooth Surface. IEEE Transactions on Geoscience and Remote Sensing, GE20(2), pp. 212-216.

Evans, D. L. et al., 1986. Multipolarization Radar Images for Geologic Mapping and Vegetation Discrimination. IEEE Transactions on Geoscience and Remote Sensing, GE-24(2), pp. 246-257.

Flerchinger, G., Lehrsch, G. \& McCool, D., 2005. FREEZING AND THAWING | Processes. In: Encyclopedia of Soils in the Environment. s.1.:Elsevier Ltd, pp. 104-110.

French, N. H. F., Kasischke, E. S., Bourgeau-Chavez, L. L. \& Harrell, P. A., 1996. Sensitivity of ERS-1 SAR to variations in soil water in fire-disturbed boreal forest ecosystems. International Journal of Remote Sensing, 17(15), pp. 3037-3053.

Henderson, F. M. \& Lewis, A. J., 2008. Radar detection of wetland ecosystems: a review. International Journal of Remote Sensing, 29(20), pp. 5809-5835.

Henry, J.-B., Chastanet, P., Fellah, K. \& Desnos, Y.L., 2006. Envisat multi-polarized ASAR data for flood mapping. International Journal of Remote Sensing, 27(10), pp. 1921-1929.

Hess, L. L., Melack, J. M. \& Simonett, D. S., 1990. Radar detection of flooding beneath the forest canopy: a review. International Journal of Remote Sensing, 11(7), pp. 1313-1325.

Huang, C., Chen, Y., Zhang, S. \& Wu, J., 2018. Detecting, Extracting, and Monitoring Surface Water From Space Using Optical Sensors: A Review. Reviews of Geophysics, 56(2), pp. 333-360.

Klemas, V., 2015. Remote Sensing of Floods and Flood-Prone Areas: An Overview. Journal of Coastal Research, 31(4), pp. 1005-1013.
Kordelas, G. A. et al., 2018. Fast and Automatic DataDriven Thresholding for Inundation Mapping with Sentinel-2 Data. Remote Sensing, 10(6).

Krasovskaia, I. \& Gottschalk, L., 2002. River flow regimes in a changing climate. Hydrological Sciences Journal, 47(4), pp. 597-609.

Kuga, Y., Whitt, M. W., McDonald, K. C. \& Ulaby, F. T., 1990. Scattering Models for Distributed Targets. In: Radar polarimetry for geoscience applications. Norwood: MA: Artech House, pp. 111-190.

Lang, M. W. \& Kasischke, E. S., 2008. Using C-Band Synthetic Aperture Radar Data to Monitor Forested Wetland Hydrology in Maryland's Coastal Plain, USA. IEEE Transactions on Geoscience and Remote Sensing, 46(2), pp. 535-546.

Lang, M. W., Townsend, P. A. \& Kasischke, E. S., 2008. Influence of incidence angle on detecting flooded forests using C-HH synthetic aperture radar data. Remote Sensing of Environment, 112(10), pp. 3898-3907.

Lindenschmidt, K.-E., Huokuna, M., Burrell, B. C. \& Beltaos, S., 2018. Lessons learned from past ice-jam floods concerning the challenges of flood mapping. International Journal of River Basin Management, 16(4), pp. 457-468.

Lindenschmidt, K. \& Li, Z., 2019. Radar Scatter Decomposition to Differentiate between Running Ice Accumulations and Intact Ice Covers along Rivers. Remote Sensing, 11(3).

Martinis, S. et al., 2015. Comparing four operational SAR-based water and flood detection approaches. International Journal of Remote Sensing, 36(13), pp. 3519-3543.

Martinis, S. \& Rieke, C., 2015. Backscatter Analysis Using Multi-Temporal and Multi-Frequency SAR Data in the Context of Flood Mapping at River Saale, Germany. Remote Sensing, 7(6), pp. 7732-7752.

Notti, D. et al., 2018. Potential and Limitations of Open Satellite Data for Flood Mapping. Remote Sensing, 10(11).

Parjanne, A., Silander, J., Tiitu, M. \& Viinikka, A., 2018. Suomen tulvariskit nyt ja tulevaisuudessa Varautuminen maankäytön, talouden ja ilmaston muutokseen, s.1.: Suomen ympäristökeskus.

Pierdicca, N. et al., 2013. Observing floods from space: Experience gained from COSMO-SkyMed observations. Acta Astronautica, Volume 84, pp. 122-133.

Pulliainen, J. T., Kurvonen, L. \& Hallikainen, M. T., 1999. Multitemporal behavior of L- and C-band SAR observations of boreal forests. IEEE Transactions on Geoscience and Remote Sensing, 37(2), pp. 927-937.

Refice, A., D'Addabbo, A. \& Capolongo, D., 2018. Flood Monitoring through Remote Sensing. Cham, Switzerland: Springer International Publishing.

Reksten, J. H., Salberg, A.-B. \& Solberg, R., 2019. FLOOD DETECTION IN NORWAY BASED ON SENTINEL-1 SAR IMAGERY. Prague, Czech Republic, s.n.

Richards, J., Woodgate, P. \& Skidmore, A., 1987. An explanation of enhanced radar backscattering from flooded forests. International Journal of Remote Sensing, 8(7), pp. 1093-1100. 
Ruzza, G. et al., 2019. Multi-Method Tracking of Monsoon Floods Using Sentinel-1 Imagery. Water, 11(11).

Sane, M., Virtanen, A. \& Repo, R., 2014. Extending the Finnish Flood Information System to Include Flood Risk Mapping. New York City, USA, s.n.

Shen, X. et al., 2019. Inundation Extent Mapping by Synthetic Aperture Radar: A Review. Remote Sensing, 11(7).

Townsend, P. A., 2001. Mapping Seasonal Flooding in Forested Wetlands Using Multi-Temporal Radarsat SAR. Photogrammetric Engineering and Remote Sensing, 67(7), pp. 857-864.

Townsend, P. A., 2002. Relationships between forest structure and the detection of flood inundation in forested wetlands using C-band SAR. International Journal of Remote Sensing, 23(3), pp. 443-460.

Tsyganskaya, V., Martinis, S. \& Marzahn, P., 2019. Flood Monitoring in Vegetated Areas Using Multitemporal Sentinel-1 Data: Impact of Time Series Features. Water, 11(9).

Tsyganskaya, V., Martinis, S., Marzahn, P. \& Ludwig, R., 2018. SAR-based detection of flooded vegetation - a review of characteristics and approaches. International Journal of Remote Sensing, 39(8), pp. 2255-2293.

Twele, A., Cao, W., Plank, S. \& Martinis, S., 2016. Sentinel-1-based flood mapping: a fully automated processing chain. International Journal of Remote Sensing, 37(13), pp. 2990-3004.

Uddin, K., Matin, M. \& Meyer, F., 2019. Operational Flood Mapping Using Multi-Temporal Sentinel-1 SAR Images: A Case Study from Bangladesh. Remote Sensing, 11(13).

Ulaby, F., Moore, R. \& Fung, A., 1982. Microwave remote sensing:Active and Passive, Volume II: Radar Remote Sensing and Surface Scattering and Emission Theory. s.l.:Addison-Wesley Publishing Company.

Ulaby, F. T., Moore, R. K. \& Fung, A. K., 1981. Microwave Remote Sensing: Active and Passive, Volume I: Fundamentals and Radiometry. s.l.:Artech House Publishers.

Unterschultz, K., van der Sanden, J. \& Hicks, F., 2009. Potential of RADARSAT-1 for the monitoring of river ice: Results of a case study on the Athabasca River at Fort McMurray, Canada. Cold Regions Science and Technology, 55(2), pp. 238-248.

Wang, Y., Hess, L. L., Filoso, S. \& Melack, J. M., 1995. Understanding the radar backscattering from flooded and nonflooded Amazonian forests: Results from canopy backscatter modeling. Remote Sensing of Environment, 54(3), pp. 324-332.

Veijalainen, N. et al., 2010. National scale assessment of climate change impacts on flooding in Finland. Journal of Hydrology, 391(3-4), pp. 333-350.

Voormansik, K. et al., 2014. Flood Mapping With TerraSAR-X in Forested Regions in Estonia. IEEE Journal of Selected Topics in Applied Earth Observations and Remote Sensing, 7(2), pp. 562 - 577.

Wu, S.-t. \& Sader, S. A., 1987. Multipolarization SAR Data for Surface Feature Delineation and Forest Vegetation Characterization. IEEE Transactions on Geoscience and Remote Sensing, GE-25(1), pp. 67-76. 